\title{
Article \\ Experimental Energy and Exergy Analysis of an Automotive Turbocharger Using a Novel Power-Based Approach
}

\author{
Sina Kazemi Bakhshmand *(D), Ly Tai Luu (D) and Clemens Biet \\ Integrated Modeling of Energy-Efficient Vehicle Powertrains, Technical University Berlin, Secretary CAR-B1, \\ Carnotstrasse 1a, 10587 Berlin, Germany; 1.luu@campus.tu-berlin.de (L.T.L.); clemens.biet@tu-berlin.de (C.B.) \\ * Correspondence: s.kazemibakhshmand@tu-berlin.de
}

check for updates

Citation: Kazemi Bakhshmand, S.; Luu, L.T.; Biet, C. Experimental Energy and Exergy Analysis of an Automotive Turbocharger Using a Novel Power-Based Approach. Energies 2021, 14, 6572. https:// doi.org/10.3390/en14206572

Academic Editor: Silvia Marelli

Received: 28 August 2021

Accepted: 10 October 2021

Published: 13 October 2021

Publisher's Note: MDPI stays neutral with regard to jurisdictional claims in published maps and institutional affiliations.

Copyright: (c) 2021 by the authors. Licensee MDPI, Basel, Switzerland. This article is an open access article distributed under the terms and conditions of the Creative Commons Attribution (CC BY) license (https:/ / creativecommons.org/licenses/by/ $4.0 /)$.

\begin{abstract}
The performance of turbochargers is heavily influenced by heat transfer. Conventional investigations are commonly performed under adiabatic assumptions and are based on the first law of thermodynamics, which is insufficient for perceiving the aerothermodynamic performance of turbochargers. This study aims to experimentally investigate the non-adiabatic performance of an automotive turbocharger turbine through energy and exergy analysis, considering heat transfer impacts. It is achieved based on experimental measurements and by implementing a novel innovative power-based approach to extract the amount of heat transfer. The turbocharger is measured on a hot gas test bench in both diabatic and adiabatic conditions. Consequently, by carrying out energy and exergy balances, the amount of lost available work due to heat transfer and internal irreversibilities within the turbine is quantified. The study allows researchers to achieve a deep understanding of the impacts of heat transfer on the aerothermodynamic performance of turbochargers, considering both the first and second laws of thermodynamics.
\end{abstract}

Keywords: turbocharger; turbine; heat transfer; exergy; power-based approach

\section{Introduction}

In the light of growing awareness of the environmental impacts of $\mathrm{CO}_{2}$-intensive processes on global warming, the need for the optimization of energy conversion systems has gained significant importance in recent decades. In particular, the global automotive industry is facing various challenges to meet emission legislation and reduce greenhouse gases. In the past few years, engine downsizing has been seen as one of the key technologies to reduce fuel consumption and emissions. This is achieved by reducing the size of the internal combustion engine (IC engine) while using the turbocharger to compensate for the power loss due to the engine size reduction. This approach consequently leads to reductions in engine weight, friction losses, fuel consumption and emissions. The key technology in question is the concept of turbocharging. A turbocharger is composed of a turbine, using the thermal energy from the hot exhaust gas from the combustion process of the IC engine and a compressor that is mechanically connected to the turbine via a rotating shaft. Recovering the mostly wasted thermal energy of the exhaust gas of the IC engine via driving the turbocharger turbine and delivering the demanded compressor power gives the required engine boost pressure.

The conventional turbocharger performance measurements on the hot gas test bench are based on the SAE J922 and SAE 1826 standards, under adiabatic assumptions. These adiabatic assumptions do not take into account the unavoidable aerothermodynamic effects of heat transfer (Figure 1). 


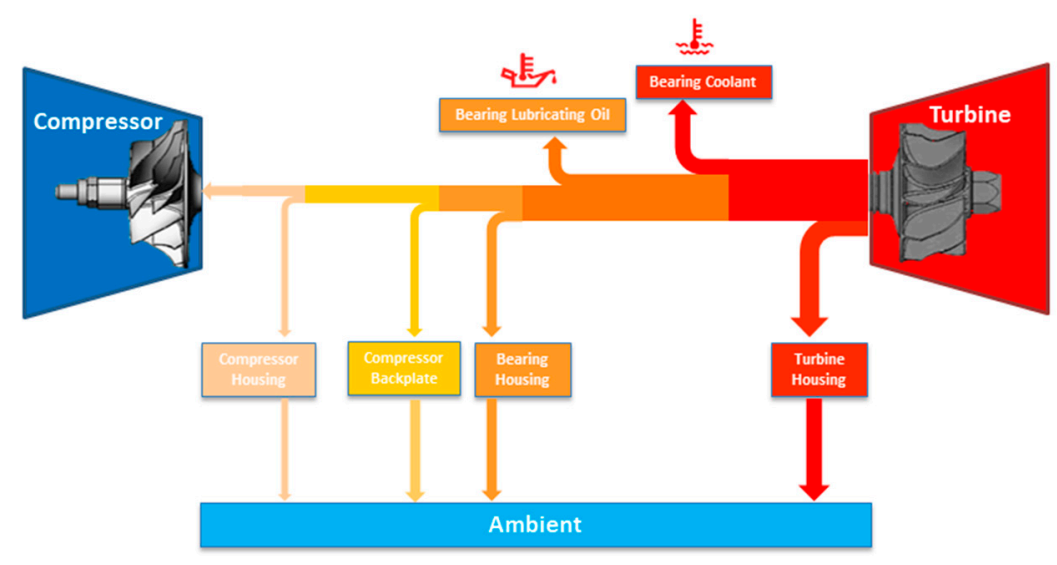

Figure 1. The heat transfer process in a turbocharger.

The diabatic (i.e., non-adiabatic) behavior and heat transfer within the turbocharger is significant, especially at low operating speeds, as the effects of the heat transfer dominate the aerodynamic turbine expansion work, leading to overestimation of the turbine power and isentropic efficiency [1]. Therefore, the characterization of heat flows in turbochargers is of great interest beyond the state of the art. Many recent studies have proposed different experimental and numerical methods that allow researchers to approximate the heat transfer within the turbochargers, including sophisticated conjugate heat transfer $(\mathrm{CHT})$ simulations of different complexities [2-4]. Most of the above-mentioned methods depend on geometric data and require extensive computational costs and measurement time. In certain studies [5,6], an experimental model has been proposed to identify the internal heat transfers to estimate the corrected turbine and compressor efficiency, which is based on certain geometrical assumptions and simplifications. As a solution to overcome these complexities, a power-based approach has been introduced first by the author of [7] that allows estimating the heat transfer rate of the turbochargers based on experimental measurements directly taken from hot gas tests. Several validations using the power-based method have been performed using CFD and CHT [8-10], showing satisfying agreement between the experimental and simulation results. The feasibility and reliability of the proposed approach have further been proven by [11], where the performance and heat transfer impacts of four different turbochargers were compared.

Thermodynamically, applying the energy balance to the turbocharger using the standard model follows the first law of thermodynamics. On the other hand, the first law of thermodynamics is not sufficient on its own to understand the aerothermodynamic behavior of the turbocharger, such as the losses caused by heat transfer and internal irreversibilities. S. M. Lim et al. have performed a numerical CFD-based exergy analysis, in which the CFD results have also been validated with the experimental data, and suggested that the aerothermodynamic performance cannot be fully depicted when based on an energetic consideration alone [1]. Furthermore, S. M. Lim et al. concluded that the amount of losses caused by heat transfer and internal irreversibilities occurs during the expansion process and fluctuates between factors of 8 and 15 for different operating points. The total irreversibilities exceed the generated power by a substantial factor and, as a result, must not be neglected [12]. A. Diango et al. have carried out an exergy analysis and optimization for the application of small turbomachines under non-adiabatic operations. In this study, a new parameter, namely, the entropic temperature has been introduced, allowing a detailed calculation of losses. They found that the performance of the turbines as generally given in adiabatic maps is overestimated and needs to be recalculated by considering the thermal losses [13]. Therefore, the traditional approach via the first law of thermodynamics does not provide adequate insight into the prevalent aerothermodynamic losses. By introducing the entropy term to quantify the irreversibility of the process, the efficiencies can be further dissected and optimized using the approach of entropy generation minimization. The idea of entropy minimization and exergy analysis is a well-documented approach to improving 
thermal systems. For this experimental research, the potentials and differences between the first and second law concepts are shown.

This study aims to further develop the aerothermodynamic investigation of a commercial vehicle turbocharger turbine as a case study. The turbocharger is measured directly on a hot gas test bench in both adiabatic and diabatic conditions. The power-based approach has been implemented for the turbocharger turbine to estimate the turbine heat losses, providing the basis for the subsequent exergy analysis. The diabatic measurements and analysis have been carried out for different turbine inlet temperatures (TIT).

\section{Materials and Methods}

\subsection{Experimental Procedure}

The turbocharger has been measured on the hot gas test bench at the chair of Integrated Modelling of Efficient Powertrain Systems at the Technical University, Berlin (Figures A1 and 2). All the tests have been conducted using a mechanical compressor, allowing for combustion air pressures up to 4 bar and mass flows of up to $1400 \mathrm{~kg} / \mathrm{h}$. The test bench is capable of producing a wide temperature range $\left(\mathrm{T}_{3}\right.$ up to $\left.1050{ }^{\circ} \mathrm{C}\right)$ either via an electrical heater or a combustion chamber. The turbine mass flow rate is measured by a thermal mass flow meter (with a measuring accuracy of up to $<0.8 \%$ of the measured value). Turbocharger rotational speed is captured using an eddy current measurement system. Pressures and temperatures have been recorded at the inlets and outlets of the turbine and compressor. Thermocouples of type $\mathrm{K}$ have been used to measure the temperatures at the exhaust side and PT100 for the compressor side, lubrication oil and coolants (for $\mathrm{T}_{3}>800^{\circ} \mathrm{C}$ ). A mixing device has been also installed in the measurement pipe downstream from the turbine to make a homogenous temperature field and increase the temperature measurement accuracy of $\mathrm{T}_{4}$, as can be seen in Figure 3 [14].

The V-element mixing device on the left-hand side of Figure 3 shows the structure of the device that has been placed downstream of the turbine, between the turbine outlet and the $T_{4}$ measurement point. On the right are the results of a numerical comparison between standard measurement pipe and mixing element, showing the significant improvement of the homogenized temperature field, which is more suited for reliable $\mathrm{T}_{4}$ measurement.

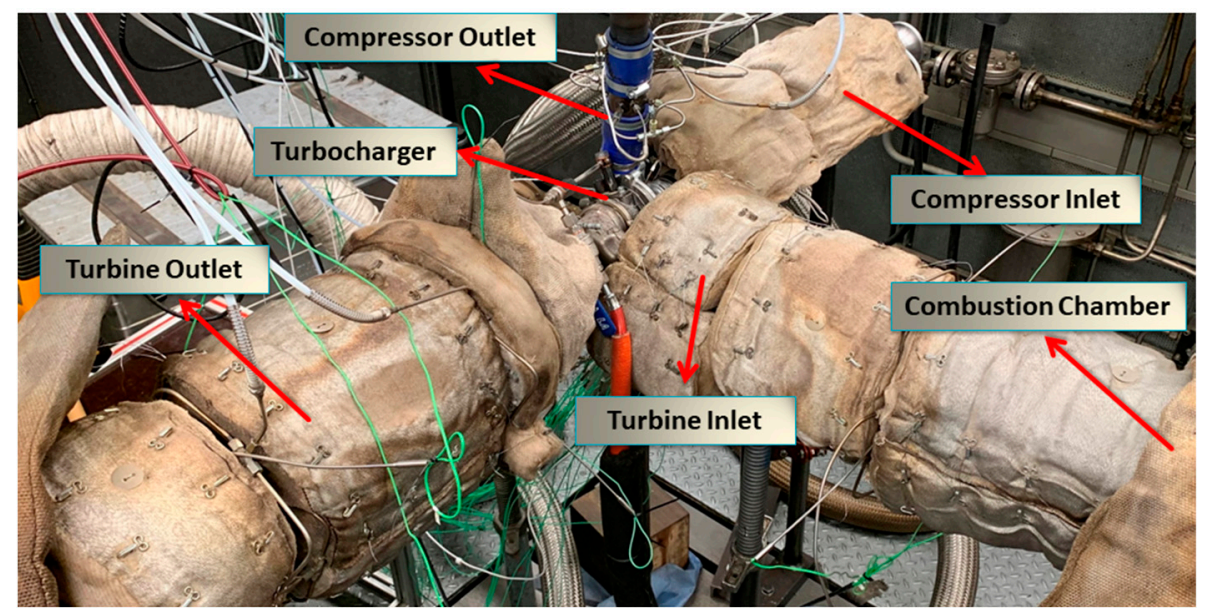

Figure 2. Turbocharger hot gas test bench at the TU Berlin. 

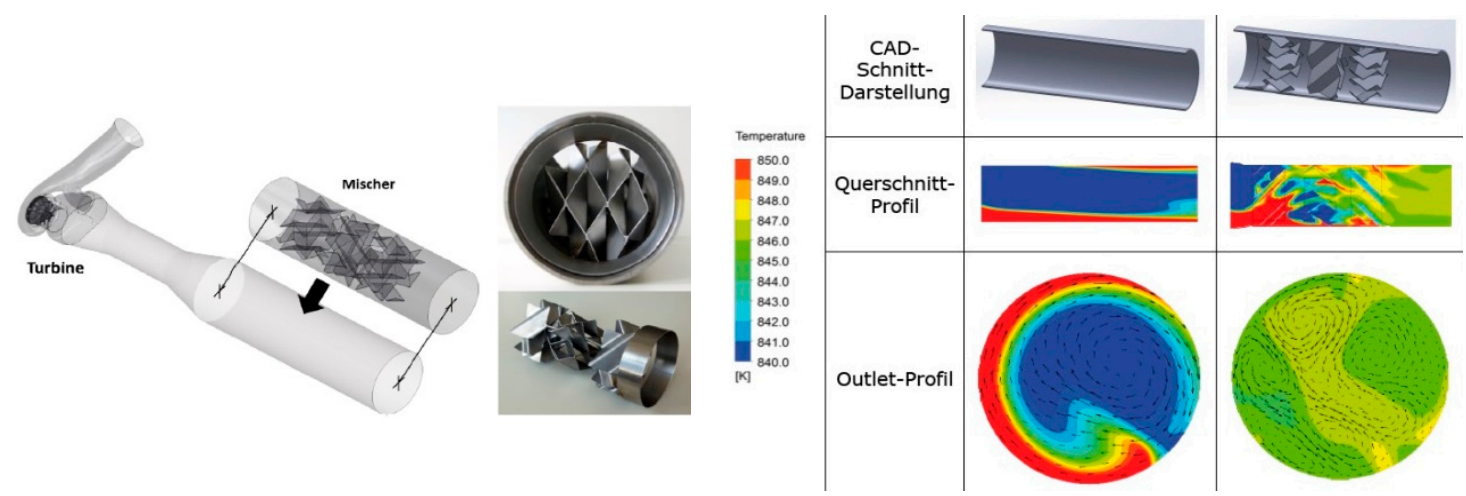

Figure 3. Mixing device (left) and temperature-mixing quality study (right) [14].

\subsubsection{Adiabatic Measurement Conditions}

Most of the common approaches for turbocharger adiabatic tests consider lower operating temperatures to prevent higher temperature gradients and heat transfer effects. The expansion and compression processes always encounter unavoidable temperature changes and gradients; therefore, it is not possible to reach adiabatic conditions at real operating points. However, the proposed near-adiabatic testing conditions follow the rule of "minimizing the diabatic behavior" through temperature adjustments. From different heat transfer analyses [15] it is proven that the lubricating oil is responsible for internal heat transfer and acts as an internal heat sink for the turbine. Matching the turbine inlet temperature with the mean oil temperature and the compressor outlet temperature $\left(\mathrm{T}_{3}=\mathrm{T}_{\text {Oil,mean }}=\mathrm{T}_{2}\right)$ is a viable method to approach near-adiabatic conditions. Additionally, keeping the operating temperatures low is generally favorable, to minimize thermal interactions between the turbocharger and environment. Furthermore, all measurement pipes and the turbocharger are insulated to minimize heat losses. It should be mentioned that throughout the adiabatic testing, the turbine power is mostly provided through the mass flow rather than the specific enthalpy (temperature) drop, which results in the measurement of fewer speed lines due to the pressure and mass flow limitations of the hot gas test bench. Moreover, the mentioned temperature alignments used to reach near-adiabatic conditions require a relatively longer measurement time in comparison to standard diabatic tests.

\subsubsection{Diabatic (i.e., Non-Adiabatic) Measurement Conditions}

The diabatic measurements used for this paper, on the other hand, exhibit turbine inlet temperatures of $400{ }^{\circ} \mathrm{C}, 600{ }^{\circ} \mathrm{C}$ and $800{ }^{\circ} \mathrm{C}$. The adjacent pipes to the turbocharger, as well as the lubricating oil and coolant pipes, were insulated. The turbocharger itself was not insulated. Although the insulations do not fully eliminate the heat losses, it was shown that they can be reduced significantly in this way [7].

\subsection{Power-Based Approach}

As mentioned earlier, the conventional turbocharger measurement SAE standard suggests a turbine inlet temperature of $600{ }^{\circ} \mathrm{C}$ while simultaneously assuming adiabatic conditions. It turns out that neglecting the effects of heat transfer in a turbocharger and assuming it as an adiabatic component would be insufficient for providing a deep understanding of aerothermodynamic effects on the turbocharger performance. Therefore, methods for measuring, modeling and determining the heat transfer in turbochargers have always presented a challenge in terms of the development and accurate prediction of turbocharger performance.

Due to this discrepancy, this standard approach is incapable of extracting turbocharger aerodynamic maps directly from the hot gas measurements.

Accordingly, a novel approach has been developed at TUB that determines the turbocharger heat transfer directly from the hot gas test bench measurement data [7]. Hence, 
the developed power-based approach can be applied as a powerful tool to extract the turbocharger heat flow directly from the hot gas test measurements. The methodology is based on characterizing effective turbine power (ETP), calculated directly from the hot gas test bench with respect to the isentropic compressor power (ICP), which is not influenced by heat transfer [7]. The isentropic compressor power (ICP) only depends on the compressor inlet temperature and the compressor pressure ratio, which are largely independent of heat transfer (Equation (1)).

$$
P_{C, i s}=\dot{m}_{C} c_{p, C} T_{1}\left(\Pi_{C}^{\frac{\kappa-1}{\kappa}}-1\right)
$$

Figure 4 illustrates how the heat flows can be estimated using a power-based diagram. It can be seen that plotting the ETP over the ICP benefits a linear fitting of the points that correspond to the maximum ICP for every speed line. The fitting lines of both diabatic and adiabatic data can be extended to intercept the ordinate. Theoretically, at the zero ETP/ICP point, the rotational speed and, thus, the friction losses are zero. Moreover, the fitting line of the operating points at maximum isentropic compressor power in adiabatic conditions indicates the origin being at the zero point. Therefore, the vertical offset between non-adiabatic and adiabatic fitting lines in the ETP axes represents the heat loss from the turbine. Consequently, heat losses can be directly extracted from the experimental data, and it is then possible to calculate the corrected aerodynamic power and isentropic efficiency of the turbine solely from the measurement data. This approach offers a reasonable trade-off between the accuracy of results and high calculation costs, through using CHT analysis as well as measurement time (in the case of adiabatic measurements) compared to standard measurement methods. In addition to that, it is independent of the turbocharger geometry information and there is not any requirement for a calibration process.

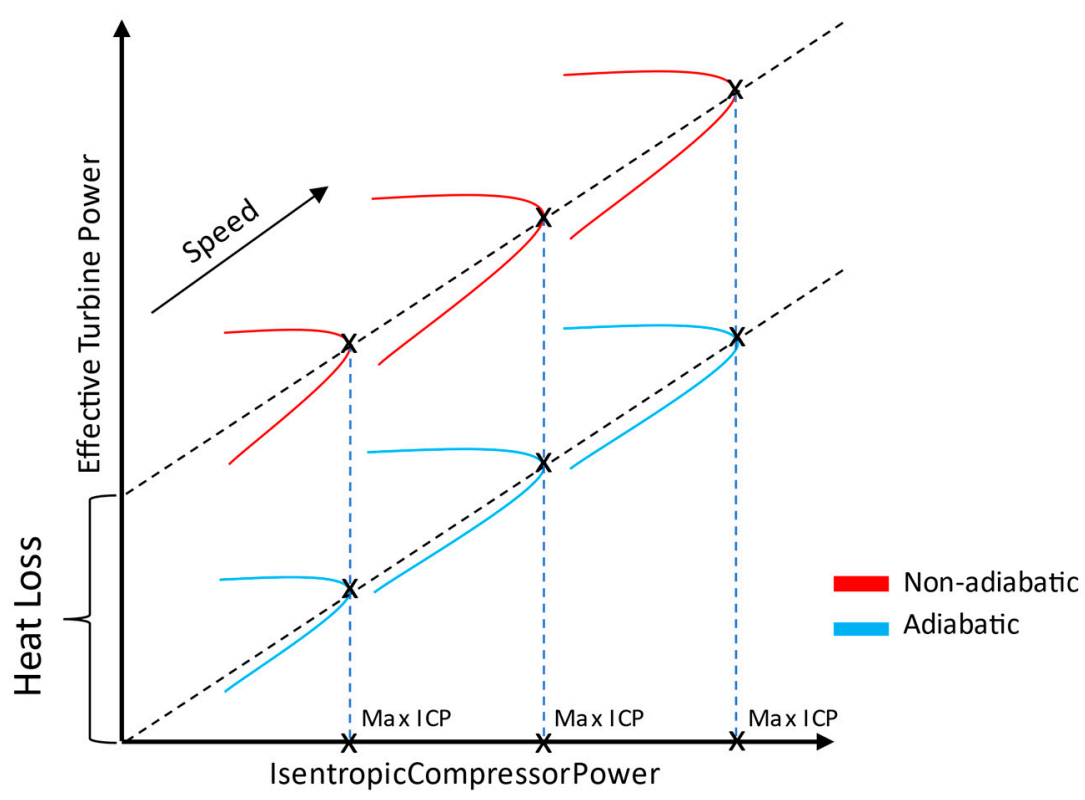

Figure 4. Power-based approach.

The following equations explain the corrected values of the turbine power and isentropic efficiency.

$$
P_{T, \text { corr }}=P_{T, e f f}-\dot{Q}_{T}
$$

The heat loss term $\dot{Q}_{T}$ can be directly estimated from the power-based method, as indicated in Figure 4 and Equation (2). Its subtraction from the total measured turbine 
power $P_{T, \text { eff }}$ (based on Equation (3)) leads to the corrected turbine power $P_{T, c o r r}$. Assuming a constant heat capacity ratio $\kappa$, the isentropic turbine power is given as (4):

$$
\begin{gathered}
P_{T, e f f}=\dot{m}_{T} c_{p, T}\left(T_{3}-T_{4}\right) \\
P_{T, i s}=\dot{m}_{T} c_{p, T} T_{3}\left[1-\left(\frac{p_{3 t}}{p_{4}}\right)^{\frac{\kappa-1}{k}}\right]
\end{gathered}
$$

Temperature and pressure are common measurement parameters and, using Equations (2)-(4), the isentropic efficiencies (5) and (6) can be estimated solely from the hot gas test bench measurement data:

$$
\begin{gathered}
\eta_{T, \text { is, uncorr }}=\frac{P_{T, \text { eff }}}{P_{T, i s}} \\
\eta_{T, \text { is, corr }}=\frac{P_{T, \text { corr }}}{P_{T, \text { is }}}
\end{gathered}
$$

\subsection{Experimental Exergy Analysis Methodology}

Thermodynamic investigations of turbochargers are often carried out with energy balances, based on the first law of thermodynamics. However, conclusions offered by the authors of $[12,13]$ clearly state that, from a thermodynamic point of view, the aerothermodynamic turbine behavior cannot be fully investigated merely using the first law of thermodynamics. Based on this research gap, further efforts, including exergy analysis, are needed to build a better thermodynamic view of heat transfer losses, one that considers the irreversibilities of every process. This study will focus on the experimental path to quantify the aerothermodynamic losses and the impact of heat transfer on a commercial vehicle turbocharger turbine. The exergy analysis, which is also referred to as second-law analysis, is based on the second law of thermodynamics. Accordingly, the calculations extend the already established energy balance.

Exergy is defined as the maximum theoretical useful work that is obtainable from a particular quantity of a substance, as the system reaches equilibrium with the environment, which is called the dead state $\left(P=P_{0} \& T=T_{0}\right)$. In this dead state, the system is in thermal and mechanical equilibrium with the environment and no turbine power can be extracted from the working fluid. The total specific flow exergy transfer associated with a stream is defined as:

$$
e_{i}=\left(h_{i}(T, p)-h_{0}\right)-T_{0}\left(s_{i}(T, p)-s_{0}\right)
$$

The following equations clarify the correlation of the first and second laws of thermodynamics, using the example of a diabatic turbine. Equation (8) represents the turbine energy balance that is adopted through (2) and (3):

$$
P_{T, \text { corr }}=\left(\dot{H}_{3}-\dot{H}_{4}\right)-\dot{Q}_{T}=\dot{m}_{T} c_{p, T}\left(T_{3}-T_{4}\right)-\dot{Q}_{T}
$$

The second law of thermodynamics, in the form of the entropy balance equation for the turbine, is defined as follows:

$$
\dot{S}_{g e n}=-\left(\dot{S}_{3}-\dot{S}_{4}\right)+\frac{\dot{Q}_{T}}{T_{b}}
$$

The working fluid is assumed to be an ideal gas with a specific heat capacity being constant between the inlet and outlet. The pressure and temperature drop during the expansion determine the entropy change, $\dot{S}_{3}-\dot{S}_{4}$, according to Equation (10):

$$
\dot{S}_{3}-\dot{S}_{4}=\dot{m}_{T}\left(c_{p} \ln \left(\frac{T_{3}}{T_{4}}\right)-R \ln \left(\frac{p_{3}}{p_{4}}\right)\right)
$$


The total entropy that is generated from the expansion process, $\dot{S}_{g e n}$, is being derived from the entropy change rate of the $\dot{S}_{3}$ and $\dot{S}_{4}$ corresponding to the turbine inlet and outlet, and the heat transfer rate term $\frac{\dot{Q}_{T}}{T_{b}}$, across the system boundary. The main objective of the exergy analysis is to figure out the main causes of the entropy generation $\dot{S}_{g e n}$. Based on Equations (9) and (10), heat transfer is identified as the main source of entropy generation. Therefore, it is important to consider the effects of heat transfer in the investigation of the turbocharger turbine. The thermodynamic average temperature $T_{b}$ of a process that undergoes a temperature change from $T_{3}$ to $T_{4}$ is given using the following equation [16]:

$$
T_{b}=\frac{T_{3}-T_{4}}{\ln \left(\frac{T_{3}}{T_{4}}\right)}
$$

Exergy can be decomposed into the following fractions:

$$
\dot{E}_{F}=\dot{E}_{P}+\dot{E}_{D}+\dot{E}_{L}
$$

where the fuel exergy term $\dot{E}_{F}$ indicates the total amount of available exergy from the turbine expansion process. The mentioned fuel exergy expression is not limited to the common understanding of fuel (such as gasoline, diesel, etc.). The individual fractions of fuel exergy are split into three different terms, as follows:

1. Product exergy $\left(\dot{E}_{P}\right):$ the produced (usable) work by a system;

2. Exergy destruction $\left(\dot{E}_{D}\right)$ : exergy destruction due to internal irreversibilities;

3. Exergy loss $\left(\dot{E}_{L}\right)$ : exergy loss due to heat losses.

The exergy destruction rate, $\dot{E}_{D}$, is an important parameter that is commonly referred to as the lost work (exergy) caused by the internal irreversibilities inside the system, and is derived as follows:

$$
\dot{E}_{D}=T_{0} \dot{S}_{g e n}=-T_{0}\left(\dot{S}_{3}-\dot{S}_{4}\right)+T_{0} \frac{\dot{Q}_{T}}{T_{b}}
$$

The exergy balance of the turbine is being carried out by combining the first and second (9) laws of thermodynamics, as follows:

$$
\underbrace{T_{0} \dot{S}_{\text {gen }}}_{\dot{E}_{D}}=\underbrace{\left(\dot{H}_{3}-\dot{H}_{4}\right)-T_{0}\left(\dot{S}_{3}-\dot{S}_{4}\right)}_{\dot{E}_{F}}-\underbrace{\underbrace{P_{T, \text { corr }}}_{\dot{E}_{P}}-\underbrace{\left(1-\frac{T_{0}}{T_{b}}\right) \dot{Q}_{T}}_{\dot{E}_{Q} \text { or } \dot{E}_{L}}}_{\text {Exergy transfer }}
$$

The exergy efficiency is thus defined as the ratio of the product exergy (turbine power) and the fuel exergy. It demonstrates the percentage of the fuel exergy wasted inside the system in the form of exergy destruction and exergy loss.

$$
\eta_{e x}=\frac{\dot{E}_{P}}{\dot{E}_{F}}=1-\frac{\dot{E}_{D}+\dot{E}_{L}}{\dot{E}_{F}}
$$

The results of the experimental analysis are featured in the following section and the impact of heat transfer and internal irreversibilities on the individual exergy terms and efficiencies are described. 


\section{Results and Discussion}

\subsection{Turbine Heat Transfer Estimation via a Power-Based Approach}

The results of the heat transfer estimation for different turbine inlet temperatures (TIT) are shown in the form of a power-based diagram in Figure 5 The investigated operating points are indicated by a circle and correspond to the highest ICP of every speed line, starting from $37 \mathrm{k} \mathrm{RPM}$ and increasing in increments of $13 \mathrm{k}$ RPM, up to $87 \mathrm{k}$ RPM for $400{ }^{\circ} \mathrm{C}$ and $800{ }^{\circ} \mathrm{C}$ TIT, and $100 \mathrm{k} \mathrm{RPM}$ for $600{ }^{\circ} \mathrm{C}$. The isentropic compressor power and effective turbine power are calculated according to Equations (1) and (3). The results of the adiabatic measurements in this diagram help to better visualize the heat loss for each diabatic scenario with respect to the adiabatic data. A line has been fitted through every maximum ICP operating point. Based on the ordinate intercept for each TIT scenario, the heat loss can be quantified to calculate the corrected turbine aerodynamic power $P_{T, c o r r}$ according to Equation (2) and, thus, also the turbine isentropic efficiency $\eta_{T, i s, c o r r}$.

It is clear from the different diagrams in Figure 5 that with an increasing TIT, the turbine heat loss rises accordingly, as steep temperature gradients are the main cause of heat transfer. The estimated turbine heat flows for different turbine inlet temperatures of $T_{3}=400{ }^{\circ} \mathrm{C}, T_{3}=600{ }^{\circ} \mathrm{C}$ and $T_{3}=800{ }^{\circ} \mathrm{C}$ are approximated to be $\dot{Q}_{T, 400}=2.6 \mathrm{~kW}$, $\dot{Q}_{T, 600}=4.9 \mathrm{~kW}$ and $\dot{Q}_{T, 800}=8.1 \mathrm{~kW}$, respectively.

Another observation can be made by comparing the different gradients of the nonadiabatic and adiabatic fitting lines. Due to the fact that the adiabatic data is the same for every diagram, with increasing TIT, the gradients show a larger offset from the adiabatic data. This means that the turbine heat transfer increases linearly with the turbocharger shaft speed. In the present work, the approximated heat transfer is considered as a mean value for each turbine inlet temperature. Although for TITs of $400{ }^{\circ} \mathrm{C}$ and $600{ }^{\circ} \mathrm{C}$, the difference is marginal, the measurement data for a TIT of $800{ }^{\circ} \mathrm{C}$ show a heat-transfer increase of up to $1.1 \mathrm{~kW}$ at the highest speed. In fact, studies by [2] prove the non-linear heat transfer behavior with increasing speed; however, aligning the gradients shows satisfying convergence with CHT simulations, as elaborated by [17]. Further calculations using the energy and exergy balances incorporate this detail.

\subsection{Exergy Analysis}

The results of isentropic turbine efficiencies (ITE) and exergetic efficiency, calculated using Equations (5) and (15), are shown in Figure 6 The results are plotted over isentropic compressor power (ICP), as a reference for comparability purposes to previous research papers regarding the power-based approach. Additionally, the heat-loss independence of the ICP adds clarity, since the highest ICP per speed line was chosen initially (c.f. circled operating points in Figure 5).

In the diabatic scenarios, the red datasets reflect the thermodynamic isentropic efficiency of the turbine that includes the effects of heat transfer. In this case, the calculated turbine power exceeds the isentropic turbine power, leading to unrealistic isentropic turbine efficiencies that are greater than 1 . Thus, heat flow correction is needed to analyze the aerodynamic performance of the diabatic turbine. 


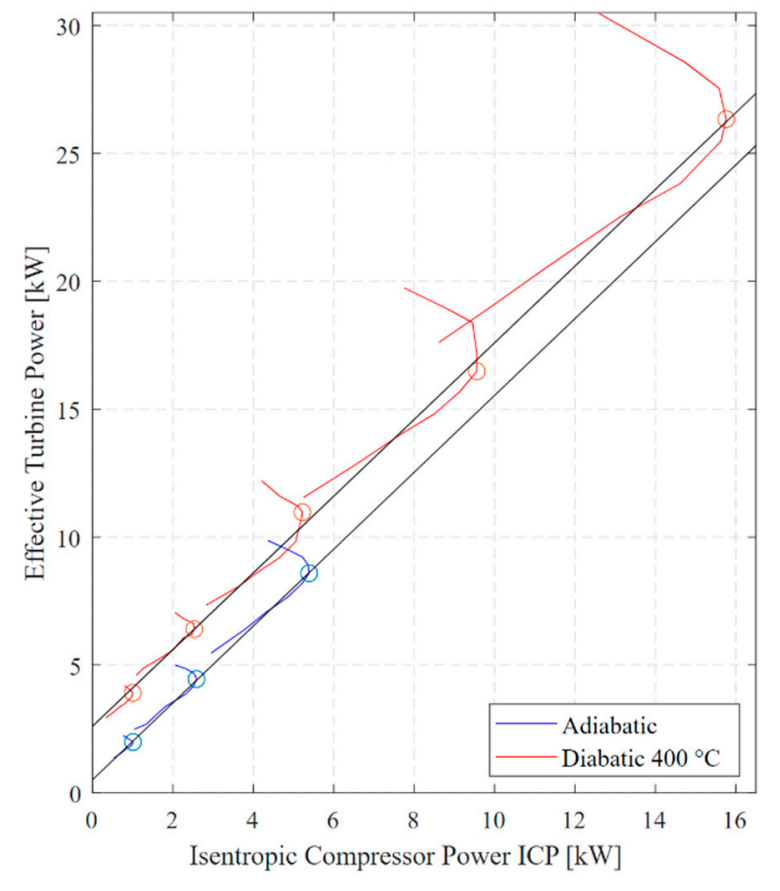

(a) $\mathrm{TIT}=400{ }^{\circ} \mathrm{C}$

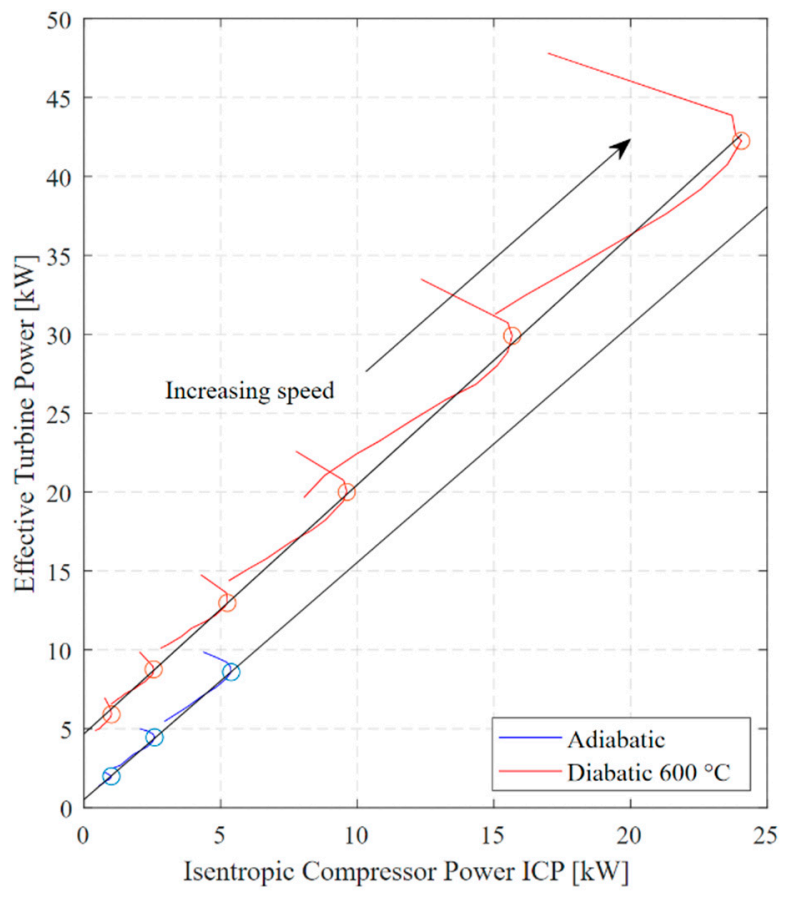

(b) $\mathrm{TIT}=600^{\circ} \mathrm{C}$

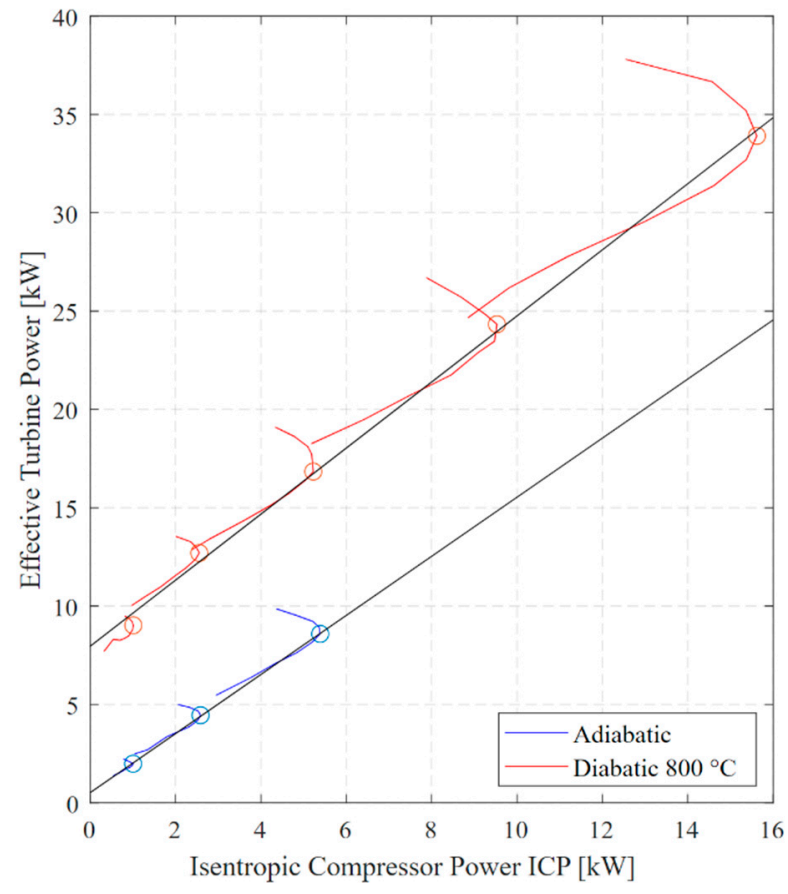

(c) $\mathrm{TIT}=800^{\circ} \mathrm{C}$

Figure 5. Power-based consideration to determine the turbine heat transfer for different $\mathrm{TIT}(\mathbf{a}) \mathrm{TIT}=400{ }^{\circ} \mathrm{C}(\mathbf{b}) \mathrm{TIT}=600{ }^{\circ} \mathrm{C}$ (c) $\mathrm{TIT}=800^{\circ} \mathrm{C}$. 


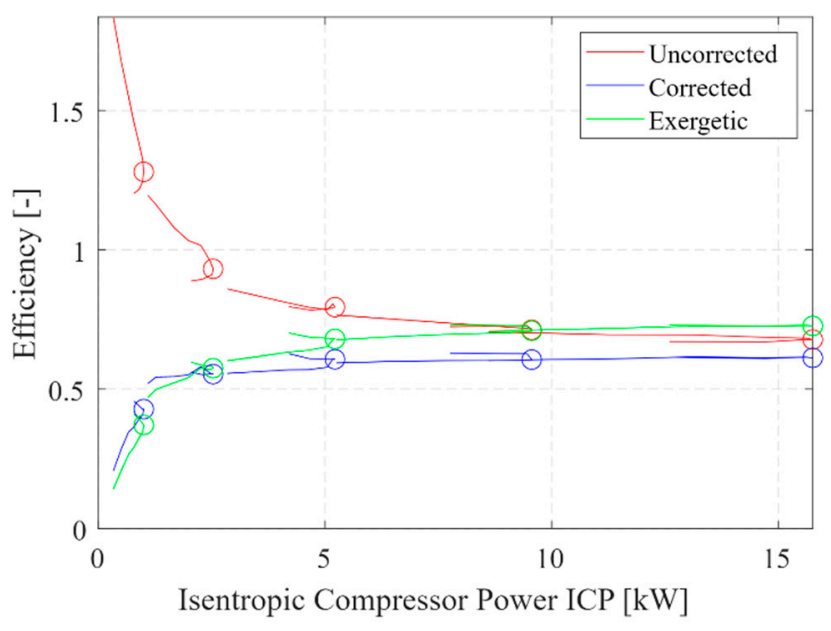

(a) adiabatic

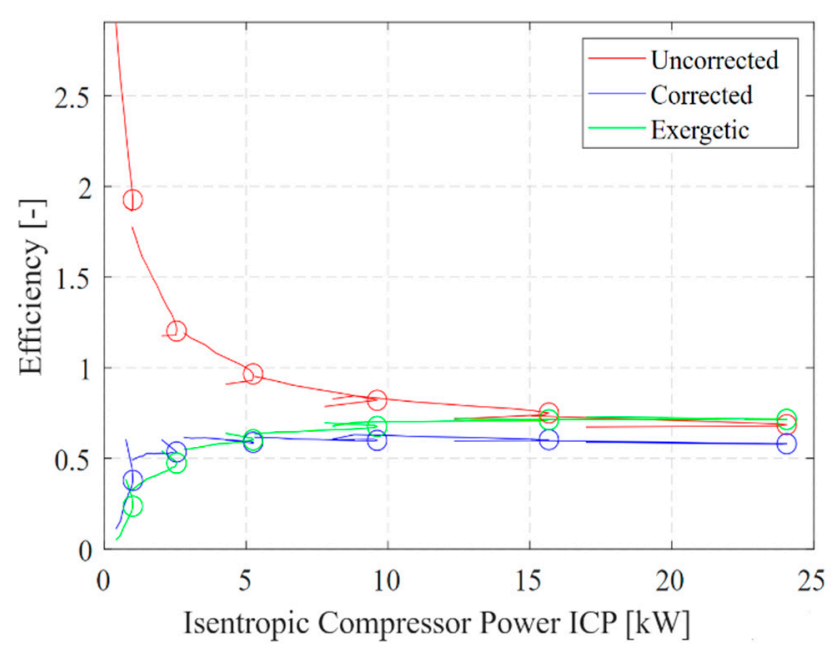

(c) $\mathrm{TIT}=600^{\circ} \mathrm{C}$

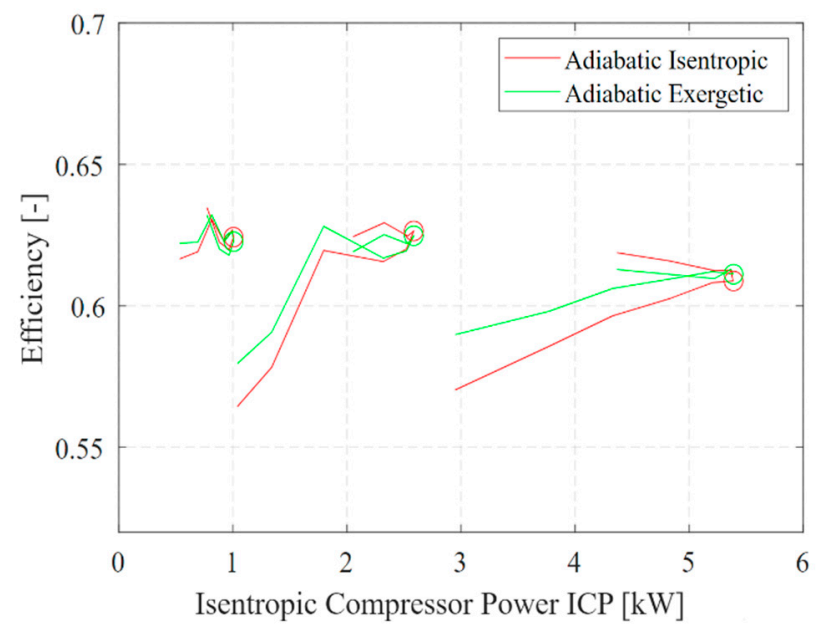

(b) $\mathrm{TIT}=400^{\circ} \mathrm{C}$

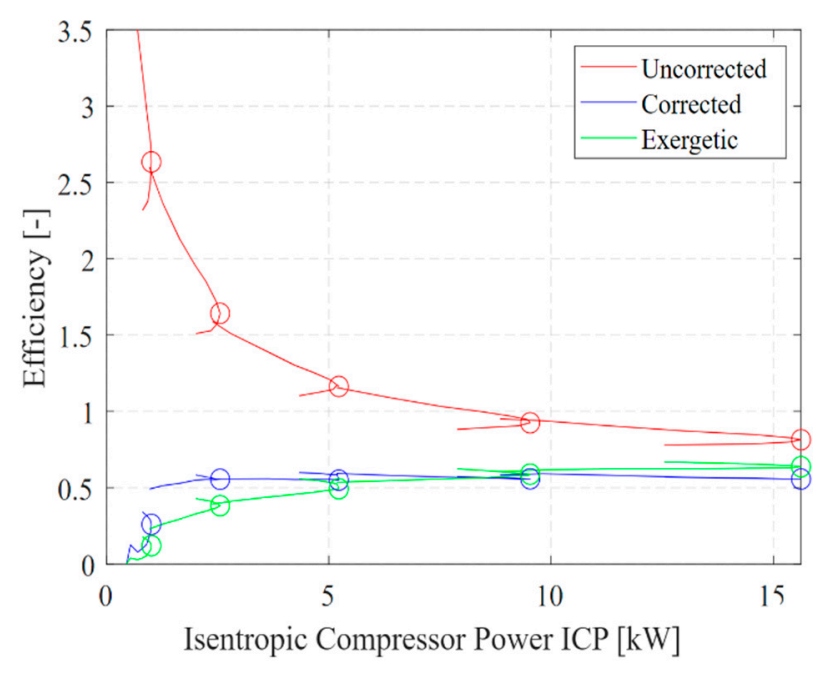

(d) $\mathrm{TIT}=800^{\circ} \mathrm{C}$

Figure 6. Different turbine efficiencies, plotted over the ICP, under different operating conditions (a) adiabatic (b) TIT $=400{ }^{\circ} \mathrm{C}(\mathrm{c}) \mathrm{TIT}=600{ }^{\circ} \mathrm{C}(\mathrm{d}) \mathrm{TIT}=800^{\circ} \mathrm{C}$.

Regarding the adiabatic results in Figure 6a, both isentropic and exergetic efficiencies are calculated through Equations (5) and (15). With the absence of heat transfer, the difference between these two efficiencies is the definition of an ideal process. Thus, in calculating isentropic efficiency, the ideal work is assumed to be a reversible adiabatic process $\left(\dot{H}_{3}-\dot{H}_{4, i s}\right)$, whereas, in calculating exergy efficiency, it is assumed to be the maximum obtainable work, which is known as fuel exergy $\left(\dot{H}_{3}-\dot{H}_{4}\right)-T_{0}\left(\dot{S}_{3}-\dot{S}_{4}\right)$. Therefore, the obtained exergetic efficiencies are higher than the isentropic efficiencies for adiabatic operation. This fact may also be extended to the diabatic performance. Thermodynamically, the exergy efficiency can be increased by reducing the heat transfer rates, ideally operating under adiabatic conditions, as explained in the following paragraphs.

The entropy change of the expansion process in the turbine can be explained in detail using the T-S diagram (Figure 7). This diagram describes a simple expansion process from state $3\left(\mathrm{~T}_{3}, \mathrm{p}_{3}\right)$ to state $4\left(\mathrm{~T}_{4}, \mathrm{p}_{4}\right)$. 


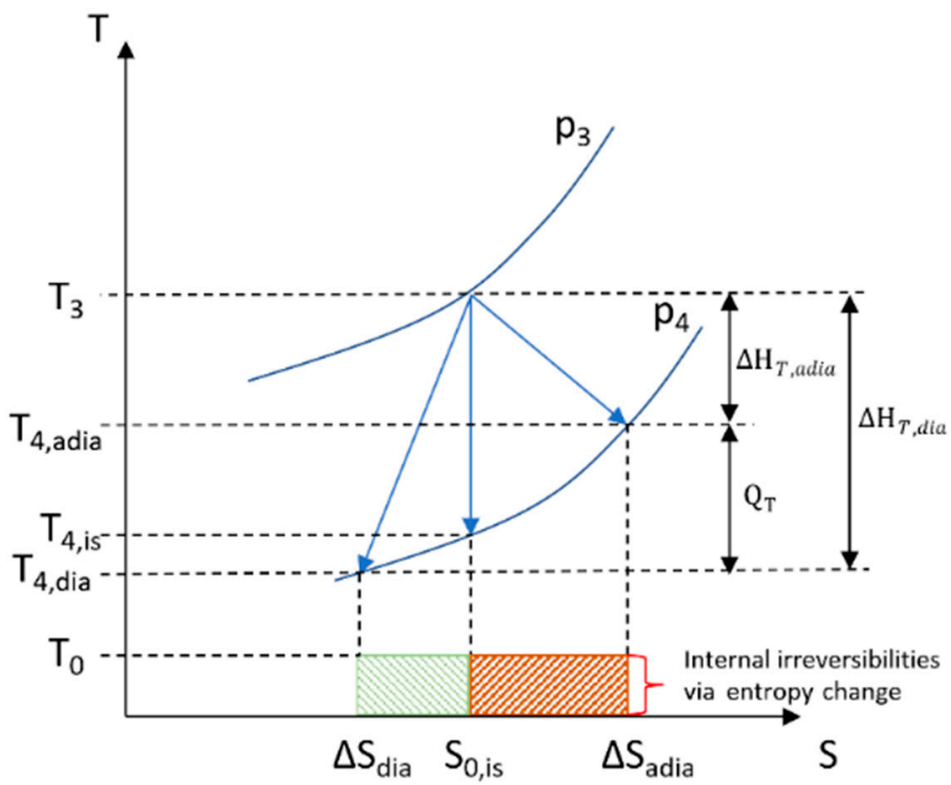

Figure 7. T-S diagram of the expansion process in a turbine.

Conventionally, isentropic efficiency uses the hypothetical isentropic temperature $\mathrm{T}_{4, \text { is }}$ to measure the efficiency of the turbine. This ideal operating point is assumed to be isentropic and results in zero entropy generation. Figure $6 b-d$, however, clearly shows that the uncorrected ITE can exceed 1, implying that the measured temperature drops below the isentropic temperature, $\mathrm{T}_{4, \mathrm{is}}$. In real operating conditions, the enthalpy (or temperature) change $\Delta H_{T, d i a}$ from the expansion can be split into the aerodynamic part $\left(\Delta H_{T, \text { adia }}\right)$, which powers the shaft, and into the thermal part $\left(Q_{T}\right)$, which additionally contributes to the temperature drop to $T_{4, \mathrm{dia}}$. The thermal influence also causes the entropy change from $\Delta S_{\text {adia }}$ toward $\Delta S_{\text {dia }}$. Combining these with Equation (9) results in the finding that heat transfer affects the internal irreversibilities and, thus, the exergy destruction rate $\dot{E}_{D}$. This phenomenon is most prevalent at lower speeds, where the heat loss influence is dominant.

Figure 8 shows the amounts of different exergy budgets, such as product exergy $\dot{E}_{P}$, exergy destruction $\dot{E}_{D}$, and exergy loss $\dot{E}_{L}$, of the turbine for all measured scenarios in a normalized form. To ensure that the comparison is consistent for every speed line, the operating points with a similar reduced turbine mass flow have been selected. The results have been normalized with the fuel exergy rate $\dot{E}_{F}$, to better understand the role of each exergy budget. From Figure 8 it is evident that both exergy losses, via internal irreversibilities, $\dot{E}_{D}$, and heat loss, $\dot{E}_{L}$, are sensitive to heat transfer. By increasing the TIT, which aims to increases the amount of heat transfer, it can be seen that the amount of exergy loss due to heat transfer in each speed line increases as well. However, by increasing the TIT, the amount of exergy destruction budget decreases; this can be explained by the fact that the exergy destruction rate varies directly with the mass flow rate, and inversely with the temperature level $\left(T_{b}\right)[16]$.

The impact of exergy loss due to heat transfer is clearly dominant, and this is the major cause of the lower exergy efficiency. Consequently, the heat loss is most dominant at lower speeds. For a TIT of $800{ }^{\circ} \mathrm{C}$ and a speed at $37 \mathrm{k} \mathrm{RPM}$ of the turbine, the exergy loss via heat transfer reaches up to $81.9 \%$, and for a TIT of $400{ }^{\circ} \mathrm{C}$, the exergy loss still contributes $41 \%$.

The results also demonstrate that by increasing the turbine speed at each TIT, the amount of exergy destruction increases as well. This is due to the fact that at higher turbocharger speeds, the mass flow of the gas also rises, which is the main cause of flow friction losses at higher speeds, and consequently leads to higher irreversibilities and exergy destruction rates. Moreover, in the adiabatic scenario because of lower operating temperatures, the specific enthalpy difference does not provide the main power of the 
turbine and mass flow is the main cause of power generation in the turbine. Therefore, higher mass flow is needed in the adiabatic scenarios to reach the same turbine power generated in the diabatic scenarios. Due to the mentioned flow friction effects at higher mass flow rates, the amounts of the exergy destruction rate in adiabatic conditions are higher than in different diabatic conditions (TIT $=400,600$ and $800{ }^{\circ} \mathrm{C}$ ). Considering the results for a TIT of $600{ }^{\circ} \mathrm{C}$, the exergy destruction between the lowest and highest speeds merely increases by $5.4 \%$, while the exergy loss via heat decreases by $47.7 \%$. As a result, the exergy destruction seems to be less affected by the turbocharger speed but is more sensitive to changes in the turbine inlet temperature.

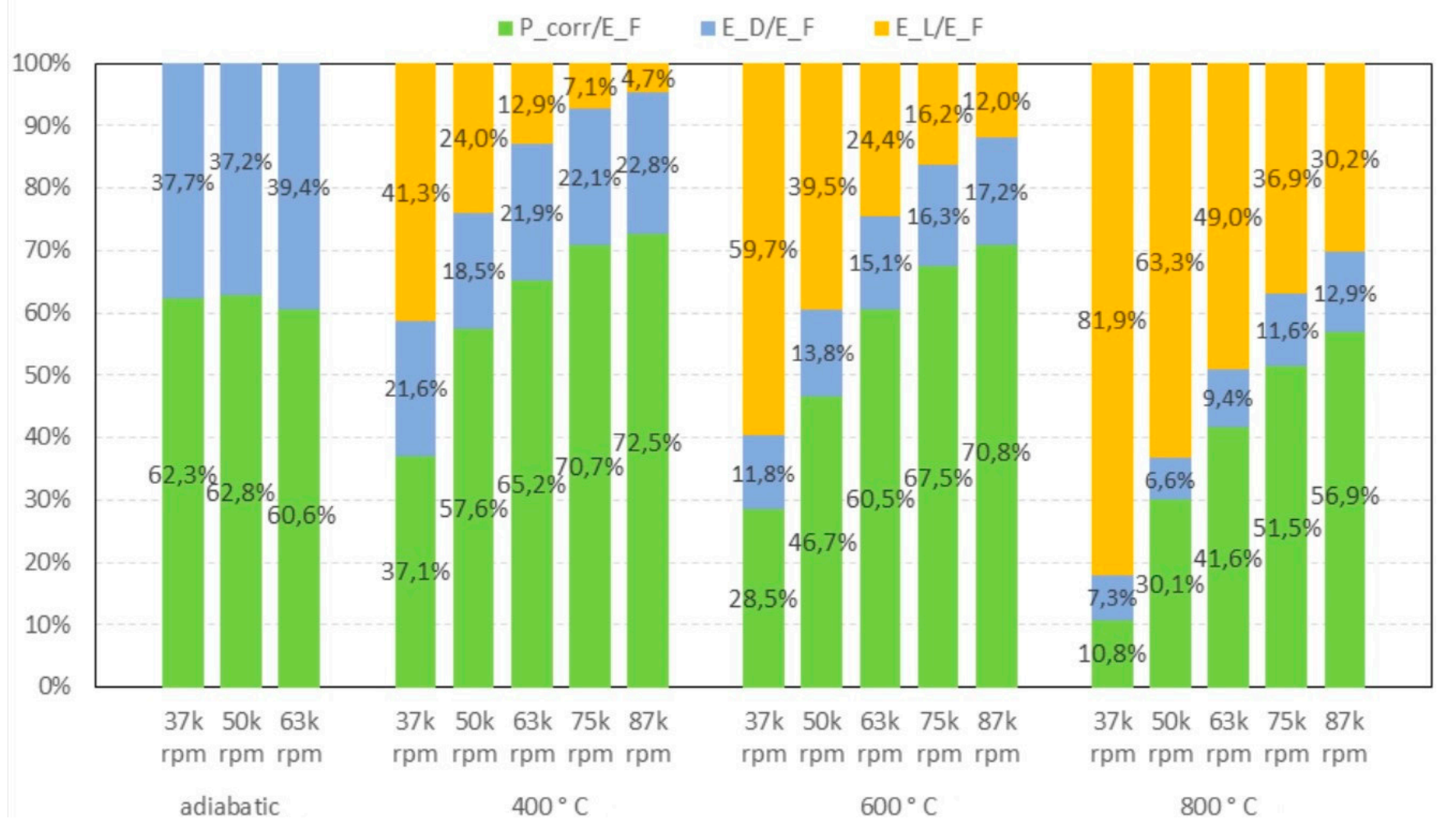

Figure 8. The turbine's normalized exergy budget at different operating points.

\section{Conclusions}

It can be concluded that the negative effect of heat loss on turbine performance is reflected in low exergy efficiencies for operating points that involve higher heat loss rates. The exergy transfer via heat transfer is also counted as exergy loss and is the major factor that reduces exergy efficiency at low speeds. It was also established that the internal irreversibilities from the expansion process are influenced by heat transfer, based on the T-S diagram. This ultimately also causes the exergy destruction of the turbine. Due to the fact that the adiabatic measurements were physically limited, higher speeds could not be recorded to compare with the non-adiabatic results. However, considering the lower exergy efficiency of the diabatic scenarios, it is considered generally favorable to minimize the heat transfer exergy losses to achieve higher efficiencies, particularly at lower speeds, through waste-heat-recovery technologies. The conventional isentropic efficiency model utilizes a hypothetical isentropic process to measure the effectiveness of the turbine. Instead, by introducing the variable of exergetic efficiency, the maximum obtainable work of the expansion is used to measure the effectiveness of the turbine. This offers a practical point of view regarding turbine efficiency, one that includes the interaction of heat transfer and internal irreversibility. The results demonstrate that by increasing the turbine speed, the amount of exergy destruction increases, which is caused by flow friction losses at upper speeds and, consequently, leads to higher irreversibilities and exergy destruction rates. 
However, the exergy destruction, in comparison to exergy loss due to heat transfer, is less affected by the turbocharger speed. Lower values of exergy efficiencies clearly show the need for further thermal optimization, especially in the case of transient operations, where unexpected conditions can occur that are not always considered in the designed operating range.

Author Contributions: Conceptualization, S.K.B.; methodology, S.K.B. and L.T.L.; formal analysis, L.T.L. and S.K.B.; experimental investigation, S.K.B.; resources, C.B.; data curation, S.K.B.; writingoriginal draft preparation, L.T.L. and S.K.B.; writing-review and editing, S.K.B. and C.B.; supervision, C.B.; project administration, S.K.B.; funding acquisition, C.B. All authors have read and agreed to the published version of the manuscript.

Funding: This research was funded by European Union's Horizon 2020 research and innovation program under grant agreement No824314. The APC was funded by the German Research Foundation and the Open Access Publication Fund of TU Berlin.

Institutional Review Board Statement: Not applicable.

Informed Consent Statement: Not applicable.

Data Availability Statement: Not applicable.

Conflicts of Interest: The authors declare no conflict of interest.

\section{Nomenclature}

$\begin{array}{ll}\text { Abbreviations } & \\ \text { CFD } & \text { Computational Fluid Dynamics } \\ \text { CHT } & \text { Conjugate Heat Transfer } \\ \text { ETP } & \text { Effective Turbine Power } \\ \text { IC } & \text { Internal Combustion } \\ \text { ICP } & \text { Isentropic Compressor Power } \\ \text { ITE } & \text { Isentropic Turbine Efficiency } \\ \text { RPM } & \text { Rotation per Minute } \\ \text { TIT } & \text { Turbine Inlet Temperature } \\ \text { Notations } & \\ T & \text { Temperature } \\ Q & \text { Power } \\ \dot{Q} & \text { Heat transfer rate } \\ \dot{m} & \text { Mass Flow Rate } \\ c_{p} & \text { Heat capacity at constant pressure } \\ \eta & \text { Efficiency } \\ \Pi & \text { Pressure ratio } \\ \dot{E} & \text { Exergy rate } \\ \dot{H} & \text { Enthalpy rate } \\ \dot{S} & \text { Entropy rate } \\ p & \text { Pressure } \\ \text { Subscripts } & \\ 0 & \text { Ambiance } \\ 1 & \text { Compressor inlet } \\ 2 & \text { Compressor outlet } \\ 3 & \text { Turbine inlet } \\ 4 & \text { Turbine outlet } \\ C & \text { Compressor } \\ \text { T } & \text { Turbine } \\ \text { B } & \text { Effective } \\ \text { eff } & \\ & \end{array}$




$\begin{array}{ll}\text { ex } & \text { Exergetic } \\ \text { is } & \text { isentropic } \\ \text { corr } & \text { corrected } \\ \text { uncorr } & \text { uncorrected }\end{array}$

\section{Appendix A}

Figure A1 demonstrates the schematic diagram of the turbocharger hot gas test bench available at the Technical University of Berlin.

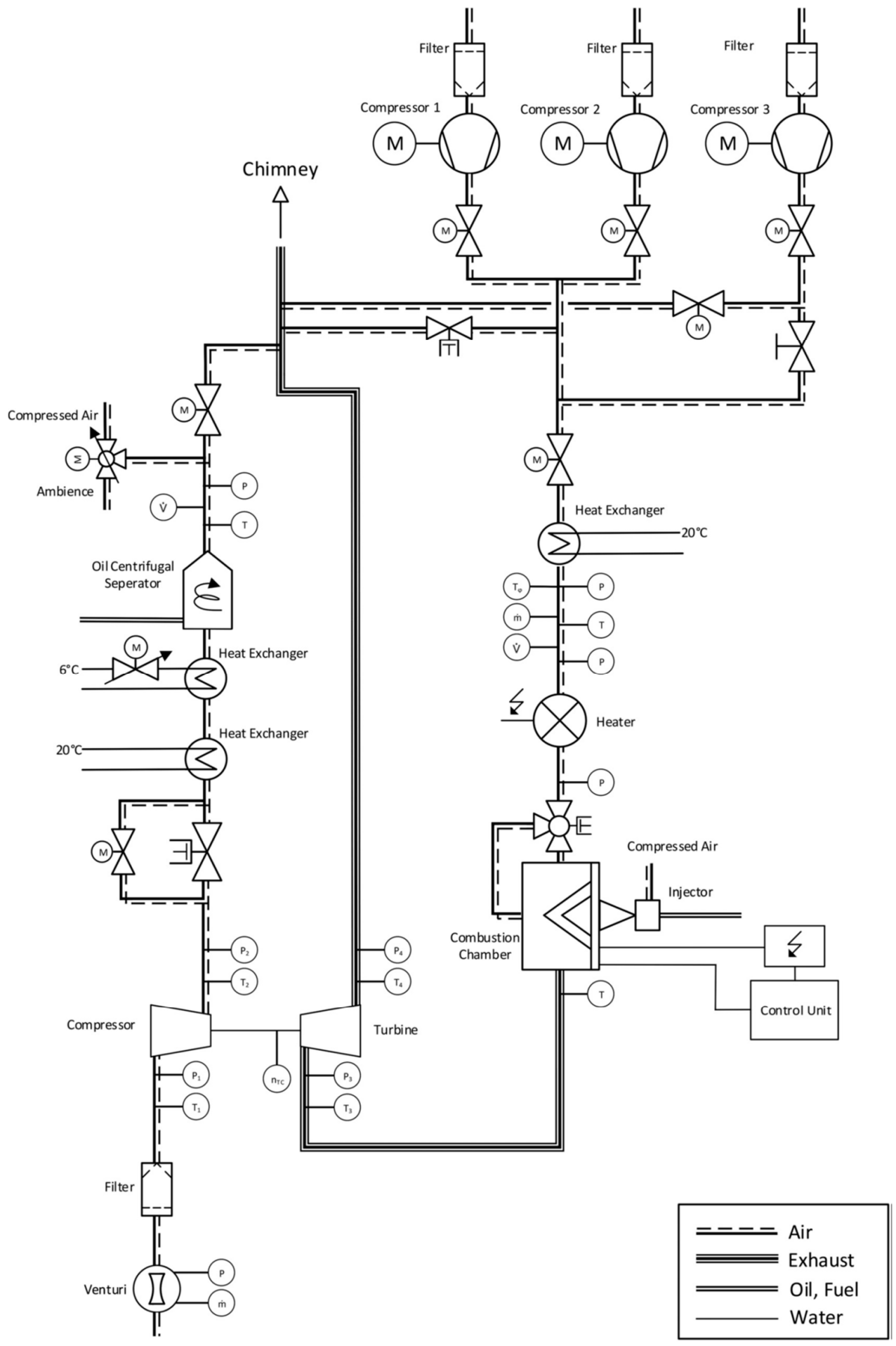

Figure A1. Turbocharger test bench at the Technical University Berlin (DIN EN ISO 10628-2, DIN 28000-4, DIN 28000-5). 


\section{References}

1. Lim, S.M.; Kazemi Bakhshmand, S.; Biet, C.; Mihaescu, M. Experimental and Numerical Investigation of a Turbocharger Turbine Using Exergy Analysis at Non-Adiabatic Conditions. In SAE Technical Paper Series; SAE Powertrains, Fuels \& Lubricants Meeting, SEP. 22, 2020; SAE International400 Commonwealth Drive: Warrendale, PA, USA, 2020.

2. Gao, X. Model of Aerodynamics and Heat Transfer of a Turbocharger. 2019. Available online: https://www.proquest.com/ openview /3c307dead97b5b5ff0b9d15728da16dd/1?cbl=2026366\&diss=y\&pq-origsite=gscholar\&accountid=14264 (accessed on 9 October 2021).

3. Aghaali, H.; Ångström, H.-E.; Serrano, J.R. Evaluation of different heat transfer conditions on an automotive turbocharger. Int. J. Engine Res. 2015, 16, 137-151. [CrossRef]

4. Payri, F.; Olmeda, P.; Arnau, F.J.; Dombrovsky, A.; Smith, L. External heat losses in small turbochargers: Model and experiments. Energy 2014, 71, 534-546. [CrossRef]

5. Marelli, S.; Gandolfi, S.; Capobianco, M. Heat Transfer Effect on Performance Map of a Turbocharger Turbine for Automotive Application. In SAE Technical Paper Series; WCX ${ }^{\mathrm{TM}}$ 17: SAE World Congress Experience, APR. 04, 2017; SAE International400 Commonwealth Drive: Warrendale, PA, USA, 2017.

6. Marelli, S.; Marmorato, G.; Capobianco, M.; Rinaldi, A. Heat Transfer Effects on Performance Map of a Turbocharger Compressor for Automotive Application. In SAE Technical Paper Series; SAE 2015 World Congress \& Exhibition, APR. 21, 2015; SAE International400 Commonwealth Drive: Warrendale, PA, USA, 2015.

7. Baar, R.; Savic, B.; Zimmermann, R. Ein neues Verfahren zur Bedatung von aerodynamischen, thermischen und mechanischen Turboladermodellen. In Der Verbrennungsmotor_Ein Antrieb mit Vergangenheit und Zukunft; Roß, T., Heine, A., Eds.; Springer: Wiesbaden, Germany, 2018; pp. 37-59. ISBN 978-3-658-19290-7.

8. Savic, B.; Zimmermann, R.; Jander, B.; Baar, R. New phenomenological and power-based approach for determining the heat flows of a turbocharger directly from hot gas test data. In Proceedings of the 12th European Conference on Turbomachinery Fluid Dynamics and Thermodynamics, Stockholm, Sweden, 3-7 April 2017.

9. Gao, X.; Savic, B.; Baar, R. Conjugate Heat Transfer Simulation of a Turbocharger Radial Turbine for Gasoline Engines. In Proceedings of the 36th CADFEM ANSYS Simulation Conference, Leipzig, Germany, 10-12 October 2018.

10. Gao, X.; Savic, B.; Baar, R. A numerical procedure to model heat transfer in radial turbines for automotive engines. Appl. Therm. Eng. 2019, 153, 678-691. [CrossRef]

11. Zimmermann, R.; Baar, R.; Biet, C. Determination of the isentropic turbine efficiency due to adiabatic measurements and the validation of the conditions via a new criterion. Proc. Inst. Mech. Eng. Part C J. Mech. Eng. Sci. 2018, 232, 4485-4494. [CrossRef]

12. Lim, S.M.; Dahlkild, A.; Mihaescu, M. Exergy analysis on Turbocharger Radial Turbine with Heat Transfer. In Proceedings of the 12th European Conference on Turbomachinery Fluid Dynamics and Thermodynamics, Stockholm, Sweden, 3-7 April 2017.

13. Diango, A.; Perilhon, C.; Descombes, G.; Danho, E. Application of exergy balances for the optimization of non-adiabatic small turbomachines operation. Energy 2011, 36, 2924-2936. [CrossRef]

14. Baar, R.; Biet, C.; Boxberger, V.; Mai, H.; Zimmermann, R. New evaluation of turbocharger components based on turbine outlet temperature measurements in adiabatic conditions. In Proceedings of the 15th International Symposium on Transport Phenomena and Dynamics of Rotating Machinery, ISROMAC 2014, Honolulu, HI, USA; 2014; pp. 24-28.

15. Baines, N.; Wygant, K.D.; Dris, A. The Analysis of Heat Transfer in Automotive Turbochargers. J. Eng. Gas Turbines Power. Apr. 2010, 132, 042301. [CrossRef]

16. Bejan, A.; Tsatsaronis, G.; Moran, M.J. Thermal Design and Optimization; Wiley: New York, NY, USA, 1996 ; ISBN 0471584673.

17. Savic, B.; Gao, X.; Baar, R. Turbocharger Heat Transfer Determination with a Power-Based Phenomenological Approach and a Conjugate Heat Transfer Validation. J. Turbomach. 2019, 141, 021011. [CrossRef] 